\title{
Clinicopathological Characteristic and Prognostic Significance of Indonesian Triple Negative Breast Cancer
}

\author{
Irianiwati Widodo $^{1, *}$, Ery Kus Dwianingsih ${ }^{1}$, Teguh Aryandono ${ }^{2}$, Soeripto ${ }^{1}$ \\ ${ }^{1}$ Department of Anatomical Pathology, Faculty of Medicine, Public Health and Nursing, Universitas Gadjah Mada, Jl. Farmako Sekip Utara, \\ Yogyakarta, Indonesia \\ ${ }^{2}$ Department of Surgery, Oncology Division, Faculty of Medicine, Public Health and Nursing, Universitas Gadjah Mada, Jl. Farmako Sekip Utara, \\ Yogyakarta, Indonesia \\ *Corresponding author. E-mail: irianiwatiwidodo@yahoo.com
}

Received date: Apr 25, 2019; Revised date: Jul 17, 2019; Accepted date: Jul 19, 2019

\section{Abstract}

B ACKGROUND: Triple negative breast cancer (TNBC) is a breast cancer subtype with negative expressions of estrogen receptors(ER), progesterone receptors (PR) and Her-2 protein receptors. This subtype exhibits aggressive behavior and poor prognosis since it is unresponsive to hormonal and Her-2 targeted therapy. The identification of clinicopathological characteristics and their prognostic values will provide guidance in developing effective treatment. This study was performed to analyze the clinicopathological characteristics and prognostic significance in Indonesian TNBC.

METHODS: Forty paraffin-embedded tissues of TNBC, stage I to IIIA, dating from 2008 to 2010 in Dr. Sardjito Hospital, were enrolled. Survival follow-up was done from January 2008 to June 2013. The samples were immunostained with ER, PR and Her-2 monoclonal antibodies to determine the TNBC subtypes. The clinicopathological characteristics were statistically analyzed. The survival was analyzed using the Kaplan Meier method. The Cox proportional hazards model was used for multivariate analysis.
RESULTS: Mean age of TNBC patients was $51.42 \pm 11.72$ years old, whereas the mean of tumor size was $5.4 \pm 2.92 \mathrm{~cm}$. Lymph node metastasis was found in $70 \%$ of cases. Number of locally advanced samples (IIIA) was 37.5\%, while moderate to high grade samples were $95 \%$. Number of still alive patients at the end of the study was $55 \%$. Number of patients that still alive up to the end of the study was $45.50 \%$. Lymph node was an independent prognostic factor for survival of TNBC patients as positive status of lymph node increases the death risk to 6 times higher $(p=0.02$, $\mathrm{RR}=6.6$ ). However, after being adjusted with age and stage, lymph node status was suggested as a modifier effect for the survival of TNBCs patients ( $R R=0.19)$.

CONCLUSION: Indonesian TNBC patients were mostly found already with large tumor size, lymph node metastasis, high pathological grade and relatively young age. Lymph node status serves as a modifier effect for the survival of Indonesian TNBC.

KEYWORDS: NBC, clinicopathological characteristics, prognostic significance

Indones Biomed J. 2019; 11(3): 286-92

\section{Introduction}

Triple negative breast cancer (TNBC) is described as a molecular subtypes of breast cancer that showed no expression of estrogen receptors (ER), progesterone receptors (PR) and Her-2 protein receptors.(1) It has been associated with African-American race, deprivation status, younger age at diagnosis, familial breast cancer and breast cancer gene (BRCA)1 mutation.(2-4) TNBC is clinicopathologically aggressive, associated with large tumor size, lymph node metastasis and high pathological grade, giving poor prognosis.(5)

TNBC is unresponsive to endocrine therapy or other available targeted agents. Thus, chemotherapy has become standard treatment for TNBC. $(6,7)$ TNBC is partly a 
basal-like subtype with the increased expression of basal cytokeratins, such as cytokeratin (CK) 5/6, CK17 and epidermal growth factor receptor (EGFR). High recurrence and poor response to chemotherapy in TNBC are probably due to the presence of basal-like cancer.(8) New effective treatment strategies for TNBCs are urgently needed, and anti-EGFR treatment is challenging to be used as targeted therapy against TNBC. $(9,10)$

The latest epidemiologic study in Asian population showed that breast cancers cases in Indonesia was reported to be 49,998 cases in 2012 (11), in which theoritically 15 $25 \%$ of it is triple negative subtype. TNBC data in Indonesia is rarely available, however it was mentioned to be occured in $25 \%$ of all cases in a clinicopathologic corellation study of breast cancer subtypes (12), and mostly occured in intermediate to high grade tumor. TNBC in Indonesia also reported to be associated with high relative death risk. (13) Survival study of TNBC in Indonesian population was reported in locally advanced TNBC with disease free survival at 5 years $11.4 \%$.(14)

Median time to relapse or death of TNBC patients are shorter than all other subtypes, and their five-year survival rates also tend to be lower. The five-year overall survival of TNBC patients was $74.5 \%$. A study of 269 TNBC subjects at the Institute of Oncology Ljubljana reported that in univariate analysis, age, nodal status, tumor size and lymphovascular invasion contributed significant impact on survival rate. Meanwhile in multivariate analysis, results showed that only nodal status was the independent prognostic factor for overall survival.(6)

Prognostic factors and markers are essential to be identified in order to choose high and low risk subsets of TNBC patients for better therapy approaches since TNBC subtypes may give different response againts specific agents. This study was performed to analyze the clinicopathological characteristics and prognostic significance of TNBC in an Indonesian population.

\section{Methods}

Research design of this study was a retrospective cohort study, with follow-up of the survival of the patients. Clinicopathological parameters, including age, tumor size, histopathological grade, staging, lymph node status were evaluated in this study. This study was ethically approved by the Institutional Review Board of the Faculty of Medicine, Public Health and Nursing, Universitas Gadjah Mada (Ref: KE/FK/248/EC 2014). Biopsy samples containing small focus of tumor were excluded. Tumor grading was determined based on morphological features, classified into low, moderate and high grade, according to the World Health Organization (WHO) classification system. Lymph node status was grouped into negative and positive lymph node metastasis. Meanwhile, cancer staging was determined using the TNM system.(15) Favorable prognostic factor criteria were patients with age $>50$ years old, size $\leq 2 \mathrm{~cm}$, low grade, no lymph node metastasis and an early stage of cancer (stage I-II), while criteria for unfavorable prognostic factors were patients with age $\leq 50$ years old, size $>2 \mathrm{~cm}$, positive lymph node metastasis, and locally advanced stage of cancer (stage IIIA).

The follow-up of patients was done in order to collect survival information, determined by weeks still alive. Survival information was collected from January 1, 2008 to June 30, 2013. Triple negative status was determined by immunohistochemical (IHC) methods using following monoclonal antibodies: 6F11 anti-ER with 1:50 dilution (Biocare, Birmingham, UK), PGR636 PR with 1:50 dilution (Biocare), CB11 Her-2 with 1:100 dilution (Biocare), Chromogen 3,3' Diaminobenzidine (DAB) and Hematoxylin Mayer counter stained. ER and PR staining were considered positive by strong nuclei reactivity in $>1 \%$ of tumor cells.(16) Her-2 staining was considered positive by strong membrane expression in $>30 \%$ of tumor cells. (17) TNBC subtype was determined when tumors were negatively stained with ER, PR and Her-2.

Correlations between each prognostic clinicopathological factor for survival of TNBC were analyzed using bivariate analysis. Survival was analyzed using product limit of Kaplan Meier estimator. Log-rank test with significance level of $<0.05$ was used to compare between favorable and unfavorable prognosis. Multivariate analysis was conducted to determine the prognostic values. To control for other prognostic values, analysis of Proportional Hazards (Cox) regression was performed.

\section{Results}

Among 40 cases of TNBC studied, the mean of patient age was $51.42 \pm 11.72$ years old, and mean of tumor size was $5.4 \pm 2.92 \mathrm{~cm}$. Lymph node metastasis was found in $70 \%$ of all cases. Number of locally advanced stage (IIIA) samples was $37.50 \%$, and samples with moderate to high grade were $95 \%$. Number of patients that were still alive at the end of the study was $55 \%$. Characteristics of the TNBC samples are shown in Table 1. 
Table 1. Characteristics of TNBC patient.

\begin{tabular}{lcc}
\hline \multicolumn{1}{c}{ Characteristics } & $\mathbf{n}(\mathbf{\%})$ & Mean \pm SD (Range) \\
\hline Age (years old) & & $51.22 \pm 11.72(32-81)$ \\
$\leq 50$ years old & $22(50 \%)$ & \\
$>50$ years old & $22(50 \%)$ & $5.40 \pm 2.9(1-15)$ \\
\hline Size (cm) & & \\
$<2 \mathrm{~cm}$ & $5(12.5 \%)$ & \\
$\geq 2 \mathrm{~cm}$ & $35(87.50 \%)$ & \\
\hline Lymph node status & & \\
Negative & $12(30 \%)$ & \\
Positive & $28(70 \%)$ & \\
\hline Histological grade & \\
Well & $2(5 \%)$ & \\
Moderate-high & $42(95 \%)$ & \\
\hline Staging & \\
Early & $25(62.50 \%)$ & \\
Locally advanced & $15(37.50 \%)$ & \\
\hline Status & & \\
Dead & $18(45 \%)$ & \\
Alive & $22(55 \%)$ & \\
\hline Survival (weeks) & \\
\hline
\end{tabular}

Univariate analysis was performed and it demonstrated that age $(p=0.05)$ and lymph node status $(p=0.02)$ were significantly associated with survival status of TNBC patients. Meanwhile, other clinicopathological factors, such as size, histopathological grade and staging were not significantly associated (Table 2 ).

Number of patient that still alive up to the end of the study was $45.50 \%$. Lymph node was suggested as

Table 2. Clinicopathologic factors analysis of TNBC subtype for survival.

\begin{tabular}{|c|c|c|c|c|}
\hline \multirow{2}{*}{ Characteristics } & \multicolumn{2}{|c|}{ Status } & \multirow{2}{*}{$p$-value } & \multirow{2}{*}{$\begin{array}{c}\text { Relative Risk } \\
95 \% \text { CI }\end{array}$} \\
\hline & Death (\%) & Alive (\%) & & \\
\hline \multicolumn{5}{|l|}{ Age } \\
\hline$\leq 50$ years old & $6(30 \%)$ & $14(70 \%)$ & \multirow{2}{*}{0.05} & \multirow{2}{*}{$0.28(0.07-1.06)$} \\
\hline$>50$ years old & $12(60 \%)$ & $8(40 \%)$ & & \\
\hline \multicolumn{5}{|l|}{ Size } \\
\hline$<2 \mathrm{~cm}$ & $3(60 \%)$ & $2(40 \%)$ & \multirow{2}{*}{0.4} & \multirow{2}{*}{$0.50(0.07-3.38)$} \\
\hline$\geq 2 \mathrm{~cm}$ & $15(42.85 \%)$ & $20(57.15 \%)$ & & \\
\hline \multicolumn{5}{|l|}{ Lymph node status } \\
\hline Negative & $2(16.16 \%)$ & $10(83.84 \%)$ & \multirow{2}{*}{0.02} & \multirow{2}{*}{$6.67(1.23-36.23)$} \\
\hline Positive & $16(57.14 \%)$ & $12(42.86 \%)$ & & \\
\hline \multicolumn{5}{|l|}{ Histological grade } \\
\hline Well & $2(100 \%)$ & $0(0 \%)$ & \multirow{2}{*}{0.45} & \multirow{2}{*}{$0.94(0.84-1.06)$} \\
\hline Moderate-high & $17(44.73 \%)$ & $21(55.27 \%)$ & & \\
\hline \multicolumn{5}{|l|}{ Staging } \\
\hline Early & $9(36 \%)$ & $16(64 \%)$ & \multirow{2}{*}{0.12} & \multirow{2}{*}{$2.67(0.72-9.95)$} \\
\hline Locally advance & $9(60 \%)$ & $6(40 \%)$ & & \\
\hline
\end{tabular}


an independent prognostic factor for survival of TNBC patients. Positive status of lymph node was demonstrated to increase the death risk until 6 times higher $(p=0.02$, $\mathrm{RR}=6.6$ ). However, adjustment was performed with age and stage, lymph node status was proposed as a modifier effect for the survival of TNBCs patients $(\mathrm{RR}=0.19)$ (Table 3, Figure. 1).

\section{Discussion}

TNBC has been described as the most aggressive subtype of breast cancer, characterized by the absence expression of estrogen, progesterone and Her-2 receptors. This subtype of breast cancer does not respond with targeted therapy, resulting in chemotherapy selected as the only choice of treatment. TNBC is often associated with poor clinicopathological outcome with a high mortality rate. $(13,18,19)$

A previous study of breast cancer in Indonesia using a large sample size (247 patients) reported that the mean age of TNBC patients was 51.84 years old, almost similar with the result of this study.(20) A study of TNBC patients in the Institute of Oncology Ljubljana showed that median age of TNBC patients was 55.3 year old, with the majority of patients (60.3\%) already in the postmenopausal phase.(6) Similar results were found by a study in Busan Paik Hospital, showing that the median age of TNBC patients was 54 years old.(21) Older-aged individuals compose nearly $20 \%$ of TNBC cases.(22) A study in Malaysia showed that median age for both TNBC and non-TNBC subtypes were 59 years old. The older median age of TNBC patients are suspected to be associated with prior family history of breast cancer and accredited to the prior use of endocrine therapy. Endocrine therapy has been previously described to minimize the risk of ER positive breast cancer.(5) However, another previous study in Malaysia reported that TNBC most likely occurred at younger ages, with mean and median age of patient of 49.4 and 48 years old, respectively.(1) Some studies in Kuwait and India also demonstrated similar results, with the median age of TNBC patients of 48 years old $(23,24)$ and 46.12 years old, respectively (25).

Different spectrum of certain biological variations may partly elaborate the age-related discrepancy in the survival of TNBC. For instance, BRCA mutations were reported to be more frequent in young breast cancer patients and exhibited poorer prognosis. $(4,26)$ However, olderaged women with TNBC showed reduced overall survival compared with the younger individuals. Senility seems to be associated with worse conditions and co-morbidities that need additional attention and monitoring that complicate the clinical management and results with an increased risk of therapy-related adverse events.(26)

According to previous study, the frequency of TNBC in Indonesian population was quite high, accounted for 29.33\%.(13) Other studies also showed high prevalence of TNBC patients among African-America patients (39\%) and Indian patients (31\%). Multiple factors may affect this condition, including early age onset of breast cancer; lifestyle factors, such as diet and obesity; reproductive factors, such as multi-parity; socio-economic status; screening behaviors and genetic susceptibility.(3,27,28)

Most of the TNBC cases in this study demonstrated large tumor size, with $87.5 \%>2 \mathrm{~cm}$ and the mean tumor size of $5.40 \pm 2.92 \mathrm{~cm}$. Furthermore, $70 \%$ of the patients showed lymph node metastasis and $95 \%$ of the cases

Table 3. Independent predictor factors analysis of TNBC subtype for survival.

\begin{tabular}{|c|c|c|c|c|c|}
\hline \multirow{2}{*}{ Prognostic factors } & \multicolumn{2}{|c|}{ Survival } & \multirow{2}{*}{$p$-value } & \multirow{2}{*}{$\begin{array}{c}\text { Unadjusted } \\
\text { (95\% CI) }\end{array}$} & \multirow{2}{*}{$\begin{array}{l}\text { Adjusted } \\
(95 \% \text { CI) }\end{array}$} \\
\hline & Death (\%) & Alive (\%) & & & \\
\hline \multicolumn{6}{|l|}{ Age } \\
\hline$\leq 50$ years old & $6(30 \%)$ & $14(70 \%)$ & \multirow{2}{*}{0.05} & \multirow{2}{*}{$0.28(0.07-1.06)$} & \multirow{2}{*}{$2.21(0.87-5.55)$} \\
\hline$>50$ years old & $12(60 \%)$ & $8(40 \%)$ & & & \\
\hline \multicolumn{6}{|l|}{ Lymph node status } \\
\hline Negative & $2(16.16 \%)$ & $12(83.84 \%)$ & \multirow{2}{*}{0.02} & \multirow{2}{*}{$6.67(1.23-36.23)$} & \multirow{2}{*}{$0.19(0.04-0.84)$} \\
\hline Positive & $16(57.14 \%)$ & $12(42.86 \%)$ & & & \\
\hline \multicolumn{6}{|l|}{ Staging } \\
\hline Early & $9(36 \%)$ & $16(64 \%)$ & \multirow{2}{*}{0.12} & \multirow{2}{*}{$2.67(0.72-9.95)$} & \multirow{2}{*}{$0.82(0.32-2.14)$} \\
\hline Locally advance & $9(60 \%)$ & $6(40 \%)$ & & & \\
\hline
\end{tabular}




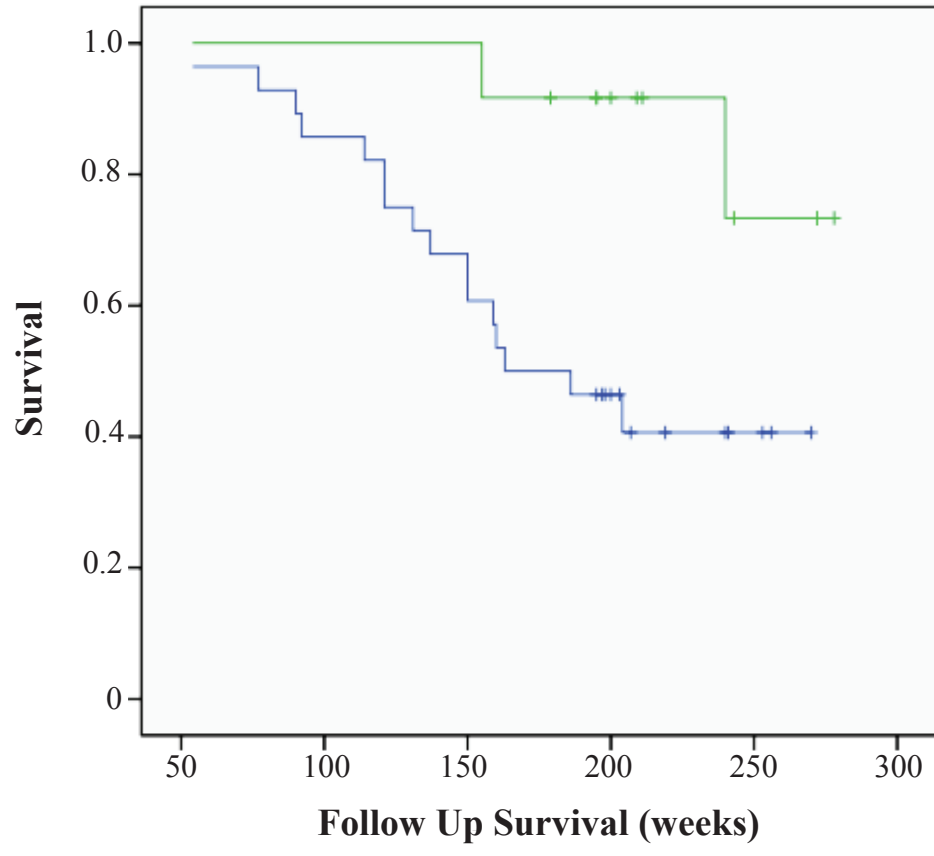

\section{Lymph node status}

$$
\begin{aligned}
& \neg \text { Positive }=28 \\
& \neg \text { Negative }=12 \\
& + \text { Positive-cencored = 16 } \\
& + \text { Negative-cencored }=2
\end{aligned}
$$

displayed moderate to poor histological grade. These results were similar to other studies showing that large tumor size indicated an aggressive behavior which was associated with more positive axillary lymph node, higher clinical stage, higher histological grade and poorer prognosis.(23,24,2931) TNBC patients also showed worse overall survival than non-TNBC patients.(32) Biological characteristics of TNBC, such as increase cell proliferation, poor differentiation, imbalances of recurrent copy number, and tumor protein (TP)53 mutations, contribute to the aggressive nature of this type of tumor.(33,34)

TNBC is frequently used as a substitute identifier of the aggressive basal breast cancer subtype since both basal-like and TNBC are related to poor clinical outcomes. The two subtypes share some similarities; however, they are not biologically-identical. The basal subtype shows an apparent expression of basal markers, such as CK5/6, CK17 and EGFR.(27,35-37) High recurrent and poor response to chemotherapy in TNBC may be caused by the presence of basal-like subtype.(8) Previous study found that the frequency of basal-like subtype in Indonesia was quite high, with $58.8 \%$. In this study, based on survival follow-up, $45 \%$ of TNBC patients died.(20) The high number of mortalities of Indonesian TNBC patients is probably due to the high frequency of basal-like subtype of breast cancer.

In this study, positive status of lymph node increased the death risk to 6 times higher and it was proposed as a modifier effect to the survival of TNBCs patients since the other causes of TNBCs patients death had not been deeply observed, such as chemotherapy effect, patient's response immune and other comorbid diseases. Therefore, further research using larger samples is necessary to be done, in order to give better insight regarding this matter. One previous study in China found that tumor size and lymph node status were significant prognostic factors for 7 year disease free survival and overall survival of TNBC patients. (38) Another study in China also supported that in TNBC patients with adjuvant chemotherapy of fluorouracil, epirubicin, and cyclophosphamide lymph node status was an independent prognostic factor of overall survival and disease free survival.(39) However, in TNBC cases with lymph node metastasis, the prognosis was not greatly affected by the number of positive lymph nodes. It is possible apart from lymphatic metastasis, hematogenous metastasis also has an important role in TNBC progression, even at an early stage.(40)

Prior studies concluded that lymph node ratio (LNR) was the independent predictor of overall survival of TNBC patients. The LNR is defined as total number of positively involved lymph nodes divided by total number of analyzed lymph nodes. It predicts survival rate more accurately compared to $\mathrm{pN}$ staging. Breast cancer staging system highlights the prognostic significance of the absolute number of positive lymph nodes. The use of LNR may standardize the staging determination and provide guidance of adjuvant therapy administration.(41-43) 


\section{Conclusion}

This TNBC study in an Indonesian population showed that TNBC patients were commonly presented with large tumor size, lymph node metastasis, high histopathological grade and relatively young age. Lymph node status was proposed as a modifier effect for the survival of TNBC patients in Indonesian population.

\section{Acknowledgements}

The authors would like to express the deepest gratitude to our colleagues and technicians from Universitas Gadjah Mada and Dr. Sardjito Hospital who provided insight and expertise that assisted the research.

\section{References}

1. Kanapathy Pillai SK, Tay A, Nair S, Leong CO. Triple-negative breast cancer is associated with EGFR, CK5/6 and c-KIT expression in Malaysian women. BMC Clin Pathol. 2012; 12: 18. doi: 10.1186/1472-6890-12-18.

2. Nguyen PL, Taghian AG, Katz MS, Niemierko A, Abi Raad RF, Boon WL, et al. Breast cancer subtype approximated by estrogen receptor, progesterone receptor, and HER-2 is associated with local and distant recurrence after breast-conserving therapy. J Clin Oncol. 2008; 26: 2373-8.

3. de Ruijter TC, Veeck J, de Hoon JP, van Engeland M, Tjan-Heijnen VC. Characteristics of triple-negative breast cancer. J Cancer Res Clin Oncol. 2011; 137: 183-92.

4. Boyle P. Triple-negative breast cancer: epidemiological considerations and recommendations. Ann Oncol. 2012; 23(Suppl 6): vi7-12.

5. Yeh J, Chun J, Schwartz S, Wang A, Kern E, Guth AA, et al. Clinical characteristics in patients with triple negative breast cancer. Int $\mathrm{J}$ Breast Cancer. 2017; 2017: 1796145. doi: 10.1155/2017/1796145.

6. Ovcaricek T, Frkovic SG, Matos E, Mozina B, Borstnar S. Triple negative breast cancer-prognostic factors and survival. Radiol Oncol. 2011; 45: 46-52.

7. Wahba HA, El-Hadaad HA. Current approaches in treatment of triplenegative breast cancer. Cancer Biol Med. 2015; 12: 106-16.

8. Changavi AA, Shashikala A, Ramji AS. Epidermal growth factor receptor expression in triple negative and nontriple negative breast carcinomas. J Lab Physicians. 2015; 7: 79-83.

9. Bao B, Mitrea C, Wijesinghe P, Marchetti L, Girsch E, Farr RL, et al. Treating triple negative breast cancer cells with erlotinib plus a select antioxidant overcomes drug resistance by targeting cancer cell heterogeneity. Sci Rep. 2017; 7: 44125. doi: 10.1038/srep44125.

10. Nakai K, Hung MC, Yamaguchi H. A perspective on anti-EGFR therapies targeting triple-negative breast cancer. Am J Cancer Res. 2016; 6: 1609-23.

11. Ghoncheh M, Momenimovahed Z, Salehiniya H. Epidemiology, incidence and mortality of breast cancer in Asia. Asian Pac J Cancer Prev. 2016; 17: 47-52.
12. Widodo I, Dwianingsih EK, Triningsih E, Utoro T, Soeripto. Clinicopathological features of indonesian breast cancers with different molecular subtypes. Asian Pac J Cancer Prev. 2014; 15: 6109-13.

13. Widodo I, Dwianingsih EK, Anwar SL, Fx Ediati T, Utoro T, Aryandono T, et al. Prognostic value of clinicopathological factors for Indonesian breast carcinomas of different molecular subtypes. Asian Pac J Cancer Prev. 2017; 18: 1251-6.

14. Khambri D, Harahap WA. Survival outcomes for Indonesian women with locally advanced triple-negative breast cancer. The breast. 2017; 32: s66. doi: 10.1016/S0960-9776(17)30226-6.

15. Lakhani SR, Ellis IO, Schnitt SJ, Tan PH, van de Vijver MJ. WHO Classification of Tumours of the Breast. 4th ed. Lyon: IARC; 2012.

16. Hammond ME, Hayes DF, Wolff AC, Mangu PB, Temin S. American society of clinical oncology/college of american pathologists guideline recommendations for immunohistochemical testing of estrogen and progesterone receptors in breast cancer. J Oncol Pract. 2010; 6: 195-7.

17. Wolff AC, Hammond ME, Schwartz JN, Hagerty KL, Allred DC, Cote RJ, et al. American Society of Clinical Oncology/College of American Pathologists guideline recommendations for human epidermal growth factor receptor 2 testing in breast cancer. J Clin Oncol. 2007; 25: 118-45.

18. Bosch A, Eroles P, Zaragoza R, Vina JR, Lluch A. Triplenegative breast cancer: molecular features, pathogenesis, treatment and current lines of research. Cancer Treat Rev. 2010; 36: 206-15.

19. Naidoo K, Pinder SE. Immunohistochemistry for triple-negative breast cancer. Methods Mol Biol. 2016; 1406: 39-51.

20. Rahmawati Y, Setyawati Y, Widodo I, Ghozali A, Purnomosari D. Molecular subtypes of Indonesian breast carcinomas - lack of association with patient age and tumor size. Asian Pac J Cancer Prev. 2018; 19: 161-6.

21. Ahn KJ, Park J, Choi Y. Lymphovascular invasion as a negative prognostic factor for triple-negative breast cancer after surgery. Radiat Oncol J. 2017; 35: 332-9.

22. Yu KD, Li JJ, Di GH, Wu J, Shen ZZ, Shao ZM. A straightforward but not piecewise relationship between age and lymph node status in Chinese breast cancer patients. PloS one. 2010; 5: e11035. doi: 10.1371/journal.pone.0011035.

23. Fayaz MS, El-Sherify MS, El-Basmy A, Zlouf SA, Nazmy N, George $\mathrm{T}$, et al. Clinicopathological features and prognosis of triple negative breast cancer in Kuwait: A comparative/perspective analysis. Rep Pract Oncol Radiother. 2014; 19: 173-81.

24. Dogra A, Doval DC, Sardana M, Chedi SK, Mehta A. Clinicopathological characteristics of triple negative breast cancer at a tertiary care hospital in India. Asian Pac J Cancer Prev. 2014; 15: 10577-83.

25. Ishitha G, Manipadam MT, Backianathan S, Chacko RT, Abraham DT, Jacob PM. Clinicopathological study of triple negative breast cancers. J Clin Diagn Res. 2016; 10: EC05-9.

26. Zhu W, Perez EA, Hong R, Li Q, Xu B. Age-related disparity in immediate prognosis of patients with triple-negative breast cancer: A population-based study from SEER Cancer Registries. PloS One. 2015; 10: e128345. doi: 10.1371/journal.pone.0128345.

27. Carey LA, Perou CM, Livasy CA, Dressler LG, Cowan D, Conway $\mathrm{K}$, et al. Race, breast cancer subtypes, and survival in the Carolina Breast Cancer Study. JAMA. 2006; 295: 2492-502.

28. Sandhu GS, Erqou S, Patterson H, Mathew A. Prevalence of triplenegative breast cancer in India: systematic review and metaanalysis. J Glob Oncol. 2016; 2: 412-21. 
29. Dent R, Trudeau M, Pritchard KI, Hanna WM, Kahn HK, Sawka CA, et al. Triple-negative breast cancer: clinical features and patterns of recurrence. Clin Cancer Res. 2007; 13: 4429-34.

30. Yang D, Liu H, Zhao J. Analysis of the clinicopathologic features and prognosis in triple-negative breast cancer. Chinese J Clin Oncol. 2008; 5: 387-90.

31. Qiu J, Xue X, Hu C, Xu H, Kou D, Li R, et al. Comparison of clinicopathological features and prognosis in triple-negative and non-triple negative breast cancer. J Cancer. 2016; 7: 167-73.

32. Li X, Yang J, Peng L, Sahin AA, Huo L, Ward KC, et al. Triplenegative breast cancer has worse overall survival and cause-specific survival than non-triple-negative breast cancer. Breast Cancer Res Treat. 2017; 161: 279-87.

33. Thompson PA, Brewster AM, Kim-Anh D, Baladandayuthapani $\mathrm{V}$, Broom BM, Edgerton ME, et al. Selective genomic copy number imbalances and probability of recurrence in early-stage breast cancer. PloS one. 2011; 6: e23543. doi: 10.1371/journal. pone. 0023543 .

34. Brewster AM, Chavez-MacGregor M, Brown P. Epidemiology, biology, and treatment of triple-negative breast cancer in women of African ancestry. Lancet Oncol. 2014; 15: e625-34.

35. Sorlie T, Tibshirani R, Parker J, Hastie T, Marron JS, Nobel A, et al. Repeated observation of breast tumor subtypes in independent gene expression data sets. Proc Natl Acad Sci USA. 2003; 100: 8418-23.

36. Nielsen TO, Hsu FD, Jensen K, Cheang M, Karaca G, Hu Z, et al. Immunohistochemical and clinical characterization of the basal-like subtype of invasive breast carcinoma. Clin Cancer Res. 2004; 10: 5367-74.
37. Morris GJ, Naidu S, Topham AK, Guiles F, Xu Y, McCue P, et al. Differences in breast carcinoma characteristics in newly diagnosed African-American and Caucasian patients: a single-institution compilation compared with the National Cancer Institute's Surveillance, Epidemiology, and End Results database. Cancer. 2007; 110: 876-84.

38. Yuan N, Meng M, Liu C, Feng L, Hou L, Ning Q, et al. Clinical characteristics and prognostic analysis of triple-negative breast cancer patients. Mol Clin Oncol. 2014; 2: 245-51.

39. Sun W, Li C, Liu M, Liu W, Yang C, Cai LI. Prognostic analysis of triple-negative breast cancer patients treated with adjuvant chemotherapy of fluorouracil, epirubicin and cyclophosphamide. Oncology letters. 2016; 11: 2320-6.

40. Chen H, Ding A, Wang M, Yin C, Zhang Z. Prognostic significance of lymph node metastasis in triple negative ductal carcinoma of the breast: a retrospective cohort study. Int J Clin Exp Med. 2017; 10: 2727-36.

41. Solak M, Turkoz FP, Keskin O, Aksoy S, Babacan T, Sarici F, et al. The lymph node ratio as an independent prognostic factor for nonmetastatic node-positive breast cancer recurrence and mortality. J BUON. 2015; 20: 737-45.

42. He M, Zhang JX, Jiang YZ, Chen YL, Yang HY, Tang LC, et al. The lymph node ratio as an independent prognostic factor for node-positive triple-negative breast cancer. Oncotarget. 2017; 8: 44870-80

43. Urru SAM, Gallus S, Bosetti C, Moi T, Medda R, Sollai E, et al. Clinical and pathological factors influencing survival in a large cohort of triple-negative breast cancer patients. BMC Cancer. 2018; 18: 56. doi: 10.1186/s12885-017-3969-y. 